\title{
Academic ethics: what has morality, culture and administration got to do with its measurement? ${ }^{1}$
}

Full Contact Information:

Dr. Gbolahan Gbadamosi

\section{${ }^{1}$ Acknowledgement:}

The author appreciates the helpful comments of Prof. Olukunle Iyanda and the anonymous reviewers on the earlier draft of this paper. 


\title{
ACADEMIC ETHICS: WHAT HAS MORALITY, CULTURE AND ADMINISTRATION GOT TO DO WITH ITS MEASUREMENT?
}

\begin{abstract}
While there is no dearth of studies on ethical issues, the specific subject of examination misconduct has attracted fewer studies especially in Africa. This study is an ongoing exploratory attempt to develop an examination misconduct measure. Self-administered questionnaires were used to collect data from 450 undergraduate business students of the Universities of Botswana and Swaziland. A nine-item measure of examination misconduct was correlated with a measure of perception of business ethics, ethical value assessment and Hofstede four dimensions of culture. Results indicated significant intercorrelations among the variables (especially the three measures of ethics) and limited construct validity for the examination misconduct scale. The result of factor analysis suggests three factors for the emerging scale: cheating behaviour, intervention and desperation. The ethical inferences of the findings, managerial implications for university administrators and practitioners, study limitations and direction for future research were discussed.
\end{abstract}

KEY WORDS: Ethics, Business ethics, Examination misconduct, Culture, Africa. 


\section{INTRODUCTION}

The term ethics generally has been used to refer to rules and principles of right and wrong conduct. It therefore boils down to morality and good or bad conduct. Business ethics is a set of rules that stipulates how businesses and their employees ought to behave (Aldag \& Stearns, 1991). Ethics is indeed a difficult and controversial concept. Ethics is about who you are and how you will conduct your business. In real life, most people have a moral sense and act accordingly habitually. There is the likelihood to assume that what is right or wrong is obvious to everyone and by including it in the workplace vocabulary everyone knows it as a policy. The challenge to managers is to be able to understand and use a middle of the road position which neither assumes ethics to be obvious and similar in everyone's understanding nor get its relevance lost in a moral discourse that would immerse the concept in theoretical waters. Ethical issues will continually be relevant in business, professional, and everyday life. Ethical issues are relevant in decision-making on every aspect of business: human resources, marketing, operations, finance, etc. Cross-cultural comparison of ethics has gained ground in academic writings with increased significance recently due to globalisation, economic integration and internationalisation of businesses leading to increased networking around the world with the world being referred to as a "global village".

Despite the plethora of studies in unethical conduct among university/college students much remains to be learned. Academic cheating behaviour is a prominent problem and it often goes unreported by faculty/professors (Rawwas \& Isakson, 2000). Brown (1995; 2000) and Rawwas \& Isakson (2000) provide a detailed account of studies on students' ethical conduct. None of these studies attempted to link academic cheating behaviour with a business ethics measure, which the present study does. This study focuses specifically on examination misconduct among undergraduate students in Botswana and Swaziland - two southern Africa countries. It is therefore, a multidimensional attempt to examine the inter-linkages and association between the following variables: perception of business ethics, ethical value assessment and examination misconduct. Examination misconduct is an important ethical issue in universities/colleges which has been significantly under-researched, at least in Africa, for reasons yet to be adduced but which could vary from a belief that researching into misconduct may suggest that it is a preponderant behaviour in the university/college or maybe country of the researcher(s). It may also be an attempt to cover up or downplay the malaise as 'not so important' among several other possibilities. This study makes three key contributions to knowledge. First, it is an attempt to develop a measuring scale for examination misconduct. Second, it also compares this new developing scale with other measures of ethics and such comparison, which helps to strengthen construct validity, has been absent in the literature. Third, few if any empirical data exist on the issue of examination misconduct in Africa, hence this study will provide comparable data with existing ones.

The use of the two Southern African countries is significant in certain respects. Both countries are relatively small with a population of about one million for Swaziland and about 1.6 million for Botswana. Whereas Swaziland - perhaps the only surviving absolute Monarchy in Africa is a monolingual country (siSwati) with very close kinship and cultural ties; Botswana is the acclaimed democratic and good governance 'success story' in Africa with 37 years of successful and uninterrupted democratic governance; also a 'nearly' monolingual country with a dominant 
national language (Setswana). Data from the two countries were intended more for cumulativeness than for comparison as the countries are more similar than different in many respects, for instance they both have only one university.

Results from empirical studies that have examined the effects of culture on ethics have consistently shown a strong relationship between the two concepts (Robertson, 1993; Schlegemilch \& Roberson, 1995). Schlegemilch \& Roberson (1995) have shown that an individual's culture and the industry of his/her occupation have the strongest influence on the perception of ethical issues. The findings of Husted et al. (1996) using MBA students across three countries - U.S.A, Spain and Mexico have also suggested that even if ethical decisions are similar, culture may affect ethical reasoning. The literature has also ascertained the following: that people from different cultures do not generally have the same values and that values are linked to ethical beliefs (Hofstede, 1980; Husted et al. 1996; Schlegemilch \& Roberson, 1995).

Four cultural values (as identified by Hofstede, 1980), which provide insight into an individual's value system, were used in this study. These are individualism as opposed to collectivism, power distance, uncertainty avoidance and masculinity as opposed to femininity. Taken together they can explain to a larger extent (along with some other variables) managerial philosophies of doing business and may guide ethical conduct. Hofstede's cultural-value measures have been very popular since Hofstede (1980) first reported it. There has been a strong argument for the importance of national culture in forming managerial values and conditioning manager's behaviour (Hofstede, 1980, 1991).

Researchers have included a wide variety of practices in their studies and have used different measuring scales, making comparison across studies in specific practices difficult (Brown, 1995). The present study attempts therefore to develop an examination misconduct scale and investigate the extent to which such a measure is associated with established ethical measures like perception of business ethics (Lin, 1999); ethical value assessment (Peppas \& Peppas, 2000); and the Hofstede’s four dimensions cultural-value measures (Hofstede, 1980).

The study also seeks to answer a number of questions, for instance:

- What are the real issues in an examination misconduct investigation? What factors should we look out for?

- What is the attitude of undergraduate students towards business ethics in Botswana and Swaziland?

- Would scores of undergraduate students be significantly associated on all three ethical measures (perception of business ethics; ethical value assessment; and examination misconduct)?

- To what extent are the ethical measures associated with the cultural dimensions?

This study will attempt to provide answers to these and other questions, and also determine the strength of association among these ethical behaviour measures and cultural dimensions in Swaziland and Botswana. The study also attempts to extend some aspects of earlier studies, specifically, Lin (1999) in an African context. The underlying assumption here is that students who are likely to be involved in examination misconduct or at least perceive it as an unacceptable behaviour would hold similar perception of business ethics and ethical value 
assessment. We may then be able to predict - albeit minimally - the ethical conduct of such students as future managers. Many cross-cultural studies were conducted with students in higher educational institutions, as they are likely to be future managers (e.g. Glenn, 1992; Khan, 1997; Lin, 1999; Preble \& Reichel, 1988; and Small, 1992).

Even though writings in the popular press have claimed that the incidence of cheating on university/college campuses have been increasing for decades, academic studies have not always supported these claims (Brown, 2000). McCabe \& Trevino (1993) found that over 67\% of students confessed to cheating at least once. While Brown (1995) reported over $80 \%$ of students in his sample admitted to committing at least one out of 15 acts of academic dishonesty. The desire to get a good grade is the most frequent reason cited for unethical behaviour (Baird, 1980; Meade, 1992; and Nuss, 1984). Other reasons cited include, lack of study time, a heavy course workload and a low risk of getting caught (Baird, 1980; Meade, 1992; and Nuss, 1984). A number of studies have also demonstrated that cheating varies inversely with the risk of detection (Leming, 1980; Tittle \& Rowe, 1973) and the perceived severity of the punishment was inversely correlated with unethical behaviour (Michaels \& Miethe, 1989). Rawwas \& Isakson (2000) found that cheating was positively related to opportunity to cheat more than any of the other variables they studied (beliefs, values and demographics); opportunity to cheat was also able to explain cheating behaviour. These findings on academic dishonesty behaviour, among others, culminated in the 'Deterrence theory' which states that a particular (unethical) behaviour is inhibited or deterred in direct proportion to (a) the perceived probability of being caught and (b) the severity of punishment of the behaviour (Buckley et al., 1998).

Burton \& Near (1995) indicated that college cheating is a type of organisational wrongdoing similar to misconduct in business organisations. But as indicated by Rawwas \& Isakson (2000) it is not enough just to identify the problem, the root of the problem must be addressed by discovering the factors behind cheating. Khan (1997) have tangentially identified the examination malpractices scourge in a study of past performance and admission criteria in Pakistan and noted it as adversely affecting the credibility and predictive accuracy in university admission criteria. Gender differences in ethical conduct, particularly, using university students as subjects has shown conflicting views as several studies found no differences between the sexes (Sikula \& Costa, 1994; Stanga \& Turpen, 1991; and Tsalikis \& Ortiz-Buonafina, 1990). Also, while Ameen et al. (1996) discovered that male students were more likely to report having engaged in unethical academic behaviour like cheating on exams or projects while in college; Buckley et al. (1998) reported that the probability of female students engaging in unethical behaviour was uniformly less than that reported by male students.

Another aspect of academic dishonesty, which has not been well captured in studies, is intervention in dishonest behaviour, specifically by other students for instance calling the attention of the examiner/invigilator. Over $80 \%$ of the economics students surveyed by Bunn, Caudill \& Gropper (1992) reported that they had observed cheating by a classmate, and 50\% admitted that they themselves had cheated on an exam or written assignment. In spite of the high incidence of cheating reported by these students, over $70 \%$ considered cheating either not a problem or a trivial problem. The main question here is whether the cooperation of these students in identifying such culprits by calling attention of the invigilators to the misconduct could make a real difference in minimising the unethical behaviour? Related to the intervention is the 
teaching of courses on ethics in schools. Stark (1993) reported over 500 business ethics courses are being taught in US colleges and $90 \%$ of business schools now provide training in ethics. Yet, Cole \& Smith (1995) indicated in their study that students' responses did not appear to be greatly influenced by whether or not they had taken ethics courses thus supporting Baron, Hammerbacher, \& Paderon (1984) who had found that beliefs held by students were not significantly influenced by such courses but by 'Business' and 'Society'. Indeed, such courses may have become part of the "furniture" as courses just to be passed to earn a degree. The question here thus remains, to what extent would the intervention behaviour (of other students) if encouraged and rewarded change the attitude and actual practice of examination misconduct?

Previous research on students' cheating behaviour can be classified into two general types: studies focusing on individual characteristics and those analysing situational and/or institutional factors (Rawwas \& Isakson, 2000). The model in Figure I depicts the various components of each segment of the unethical conduct and the possible interrelationships.

Figure I: Correlates of Students Unethical Behaviour

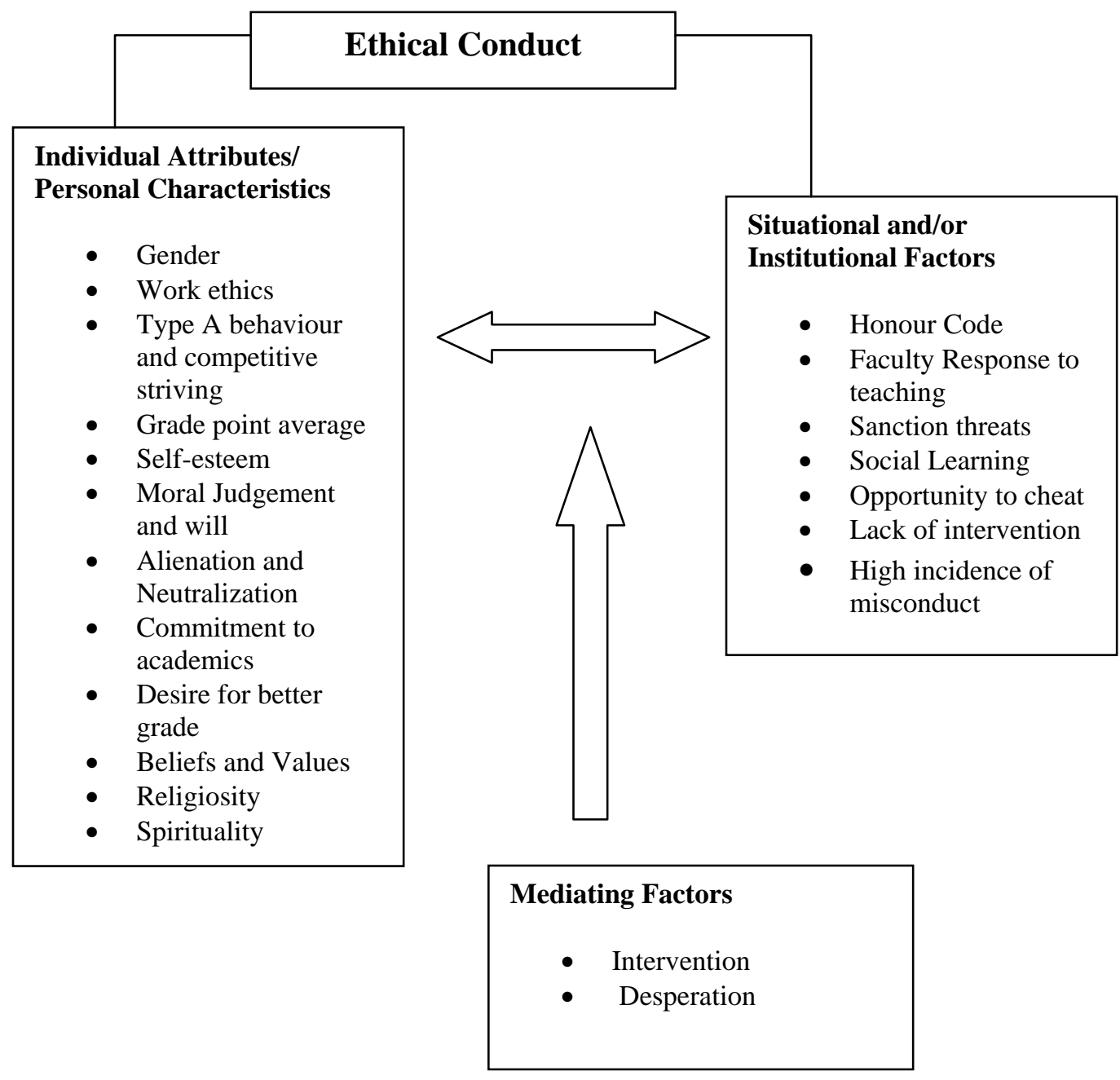




\section{RESEARCH METHODOLOGY}

The general purpose of the study is to examine the ethical behaviour of undergraduate students and specifically to investigate to what extent their attitude towards examination misconduct is associated with it.

\section{Instrument}

In developing the research methodology, several aspects of related studies in business ethics were taken into consideration. The instrument reflects components of previous studies and new ones to provide further information into the study variables.

The research instrument contained four parts. The first three parts were measured on a 5-point Likert-type scale from "5" representing "Strongly Disagree" to " 1 " representing "Strongly Agree”. The fourth part seeks demographic information.

1. Measures of Perception of Business Ethics: a 30-item measure of business ethics adaptation of Small (1992) that was used by Lin (1999) was also adopted for this study.

2. Ethical Value Assessment: this 8-item component was adapted for this study building on the measures of Peppas \& Peppas (2000).

3. Examination Misconduct Scale: this comprised a 9-item 5-point Likert type scale. The instrument is intended to assess the level of involvement in examination misconduct and also seek students' opinion of examination misconduct within the university. The nine items are shown in Table IV.

4. Measure of Culture: four dimensions of culture were measured with a 22-item scale of Hofstede. The scale was obtained from Clugston, Howell, \& Dorfman, (2000) adaptation of Hofstede. It measures four dimensions of culture namely: individualism-collectivism (6 items), power distance (6 items), uncertainty avoidance (5 items) and masculinityfemininity (5 items). They were all measured on a 5-point Likert type scale.

5. Biographic Data: gender, marital status, age, and work experience were the major demographic variables obtained.

\section{Participants}

Data was collected from undergraduate students in the Faculty of Business of the University of Botswana and Faculty of Commerce of the University of Swaziland. The participants were all students of Accounting \& Finance, Management, and Marketing in both universities. These students are ultimately likely to occupy managerial positions in the private and public sectors of the economy of both nations after completion. A total of 600 copies of questionnaires (300 in each university) were distributed to the target students. A total of 473 questionnaires were returned with 450 being complete and useable questionnaires representing $76 \%$ response rate ( 246 or $82 \%$ from Swaziland and 204 or $68 \%$ from Botswana). A total of 23 questionnaires were returned unusable (17 from Botswana and 6 from Swaziland) representing only 5\% of the returned questionnaires.

\section{ANALYSIS AND RESULTS}

In this exploratory study, we seek to investigate ethical misconduct in examinations among undergraduate business students and compare such misconduct with other ethical measures like 
perception of business ethics and ethical value assessment as well as explore the relationship of these ethical measures and culture. This would enable us to make some limited predictions about ethical behaviour of these future business managers. The demographic profile of the respondents is illustrated in Table 1. There were about 46 percent male respondents, with about 86 percent being unmarried, over 70 percent being under 25 years and about 44 percent who have never worked before. The distribution of this data is similar for both countries.

Table I: $\quad$ Summary of Sample Characteristics

\begin{tabular}{|c|c|c|c|c|c|c|}
\hline \multirow[t]{2}{*}{ Characteristics } & \multicolumn{2}{|c|}{ Total Respondent } & \multicolumn{2}{|c|}{ Botswana } & \multicolumn{2}{|c|}{ Swaziland } \\
\hline & $\%$ & Jumber & $\%$ & Number & $\%$ & Number \\
\hline \multicolumn{7}{|l|}{ Gender } \\
\hline Male & 45.6 & 205 & 45.1 & 92 & 45.9 & 113 \\
\hline Female & 54.4 & 245 & 54.9 & 112 & 54.1 & 133 \\
\hline \multicolumn{7}{|l|}{ Marital Status } \\
\hline Married & 14.3 & 64 & 15.8 & 32 & 13.0 & 32 \\
\hline Unmarried & 85.7 & 382 & 84.2 & 171 & 85.8 & 211 \\
\hline \multicolumn{7}{|l|}{ Age } \\
\hline Below 20 & 4.0 & 18 & 2.9 & 6 & 4.9 & 12 \\
\hline $21-25$ & 70.2 & 316 & 69.1 & 141 & 71.1 & 175 \\
\hline $26-30$ & 15.3 & 69 & 13.7 & 28 & 16.7 & 41 \\
\hline 31-35 & 7.8 & 35 & 11.3 & 23 & 4.9 & 12 \\
\hline $36-40$ & 1.3 & 6 & 2.0 & 4 & 0.8 & 2 \\
\hline Over 40 & 1.3 & 6 & 1.0 & 2 & 1.6 & 4 \\
\hline \multicolumn{7}{|l|}{ Work Experience } \\
\hline 0 years & 44.7 & 199 & 55.0 & 111 & 36.2 & 88 \\
\hline Below 1 year & 12.9 & 58 & 5.9 & 12 & 18.9 & 46 \\
\hline $1-2$ & 24.3 & 108 & 19.8 & 40 & 29.6 & 68 \\
\hline $3-5$ & 7.2 & 32 & 5.4 & 11 & 8.7 & 21 \\
\hline $6-10$ & 8.4 & 38 & 10.9 & 22 & 6.6 & 16 \\
\hline Over 10 years & 2.2 & 10 & 3.0 & 6 & 1.6 & 4 \\
\hline
\end{tabular}

$\mathrm{N}=450$. Note: The percentages are the valid percent.

Table II: Comparative Mean, Median \& Standard Deviation for Study Variables

\begin{tabular}{|c|c|c|c|c|c|c|c|c|c|c|}
\hline \multirow[t]{2}{*}{$\mathbf{S} / \mathbf{N}$} & \multirow[t]{2}{*}{ Study Variables } & \multicolumn{3}{|c|}{ Botswana } & \multicolumn{3}{|c|}{ Swaziland } & \multicolumn{3}{|c|}{ Total } \\
\hline & & Mean & Median & $\begin{array}{l}\text { Std. } \\
\text { Dev. }\end{array}$ & Mean & Median & $\begin{array}{l}\text { Std. } \\
\text { Dev. }\end{array}$ & Mean & Median & $\begin{array}{l}\text { Std. } \\
\text { Dev. }\end{array}$ \\
\hline 1 & $\begin{array}{l}\text { Individualism } \\
\text { Collectivism }\end{array}$ & 19.48 & 21.00 & 4.38 & 19.27 & 20.00 & 4.12 & 19.37 & 20.00 & 4.23 \\
\hline 2 & Power Distance & 19.48 & 13.00 & 4.38 & 19.27 & 13.00 & 4.12 & 19.37 & 13.00 & 4.23 \\
\hline 3 & Uncertainty Avoidance & 19.82 & 20.00 & 3.56 & 20.77 & 21.00 & 3.28 & 20.34 & 21.00 & 3.44 \\
\hline 4 & Masculinity/Femininity & 10.23 & 9.00 & 4.48 & 11.09 & 11.00 & 4.71 & 10.70 & 10.00 & 4.62 \\
\hline 5 & $\begin{array}{l}\text { Perception of Business } \\
\text { Ethics }\end{array}$ & 87.47 & 87.50 & 12.22 & 87.63 & 88.00 & 10.21 & 87.56 & 88.00 & 11.16 \\
\hline 6 & $\begin{array}{l}\text { Ethical Values } \\
\text { Assessment }\end{array}$ & 26.24 & 26.00 & 3.65 & 26.54 & 26.00 & 3.93 & 26.41 & 26.00 & 3.81 \\
\hline 7 & $\begin{array}{l}\text { Examination } \\
\text { Misconduct Scale }\end{array}$ & 25.72 & 26.00 & 5.02 & 26.04 & 26.00 & 4.25 & 25.89 & 26.00 & 4.62 \\
\hline
\end{tabular}

N= 450 [Botswana: $n$ - 204; Swaziland: $n$ - 246] 
Table III - Intercorrelations Among Study Variables

\begin{tabular}{|c|c|c|c|c|c|c|c|c|}
\hline $\mathrm{S} / \mathrm{N}$ & Study Variables & 1 & 2 & 3 & 4 & 5 & 6 & 7 \\
\hline 1 & Individualism Collectivism & (.63) & .07 & .05 & $.11^{*}$ & $.17^{* *}$ & $.15^{* *}$ & .03 \\
\hline 2 & Power Distance & & (.57) & $-.19 * *$ & $.29 * *$ & $.21^{* *}$ & .03 & .07 \\
\hline 3 & Uncertainty Avoidance & & & (.78) & $-.19 * *$ & $.13^{* *}$ & $.24^{* *}$ & $.11 *$ \\
\hline 4 & Masculinity/Femininity & & & & (.81) & $.28^{* *}$ & .01 & .01 \\
\hline 5 & Perception of Business Ethics & & & & & (.73) & $.35^{* *}$ & $.19 * *$ \\
\hline 6 & Ethical Values Assessment & & & & & & (.64) & $.13^{* *}$ \\
\hline 7 & Examination Misconduct Scale & & & & & & & (.77) \\
\hline
\end{tabular}

Means, standard deviations and correlation coefficients were calculated to present the general results of the study as shown in Tables II and III. As one might expect, the examination misconduct measures were positively and significantly correlated with both the perception of business ethics and ethical value assessment indicators at $99 \%$ level of confidence. Likewise, the correlation between perception of business ethics and ethical value assessment were positive and significant also at $99 \%$ level of confidence. In other words, the relationship between each of the three variables with each other increased as the corresponding variable increased. The explanation for this is that ethics in one aspect of life cannot be logically and cognitively different from the other. For cognitive consonance, a person's belief of what is ethical and acceptable should not differ in examination conduct, for instance, from business practice. For this to occur, there would be elements of cognitive dissonance or other explanations in the measuring indicators. Indeed, students who manifest low ethical conduct in their examination in the university are likely to equally exhibit unethical practices as managers in organisations. The reliability coefficients for this study (Cronbach alpha) for the measures of this research are reported in the diagonal of Table III. It indicates high reliability coefficients for all the scales.

The results on the correlation between the four dimensions of culture (individualismcollectivism, power distance, uncertainty avoidance and masculinity-femininity) and the ethical measures are also interesting. The perception of business ethics was significantly correlated with all the four dimensions of culture; ethical value assessment was significantly correlated with only individualism-collectivism and uncertainty avoidance, while the examination misconduct scale was significantly correlated with only uncertainty avoidance. Uncertainty avoidance indicates the extent to which a culture programmes its members to feel either comfortable or uncomfortable in structured situations. This is one variable that is significantly correlated with all the ethical measures in this study, a possible indication of a strong association between ethical conduct and risk aversion.

Much as the result in Table III established a strong and significant association between examination misconduct and perception of business ethics, it does not tell us by how much one will change as a result of the other changing. Regression analysis was carried out to determine the effect of examination misconduct on perception of business ethics. Results revealed $\mathrm{R}^{2}=$ 0.038 , Adjusted $\mathrm{R}^{2}=0.036$, F-value $(17.64$, DF 1,446$) \mathrm{p}<0.001$, showing that the results is unlikely to have arisen by sampling error hence examination misconduct is predictive of business ethics. 
In Table II, perception of business ethics for all respondents shows a mean score of 87.56, median score of 88.00, with the minimum score being 43.00 and maximum score being 138.00 (range - 95.00). For ethical value assessment, the mean score is 26.41, median score of 26.00 (minimum score - 13.00, maximum score - 36.00, range - 23.00). Examination misconduct scale has a mean score of 25.89, median score of 26.00 (minimum score 9.00, maximum score 44.00 , range -35.00 ). For these three measures, the higher the score the lower the propensity to engage in misconduct. The high scores indicate high ethical standards (value) on the items. A score below 27.00 on the examination misconduct scale, for instance, means a low ethical standard on the items on the scale. The mean scores on the four dimensions of culture are very similar perhaps suggesting the similarity in cultural values of both countries. For all the three ethical measures, students of Swaziland had slightly higher mean scores than their Botswana counterpart. While this may be insufficient to make generalisations and reach conclusions that they are more ethical, there is however a consistency in this trend as it applies to all the three variables of this research interest.

The result of the nine-item (five-point Likert type scale) measure of examination misconduct is shown in Table IV. Albeit, 79 percent of the respondents claim that they would not cheat in an examination and about 62 percent claim that they have never cheated in an examination; it is interesting that about 63 percent of the respondents would not call the attention of the invigilator if they found a fellow student cheating and about 56 percent would seek assistance from a neighbour in an examination if necessary. It is equally ironical that about 54 percent agrees that it is not their business to report a student cheating in an examination or alert the invigilators and about 56 percent agrees that students must pass examinations by all means. The responses to the other three items on the scale are spread almost evenly over the five options. There is also a high level of indifference to reporting another student who is cheating (see item 4 in Table IV).

\section{Table IV: Developing a Measure of Examination Misconduct}

\begin{tabular}{|lccccccc|}
\hline \multicolumn{1}{|l}{ Examination Malpractices Scale Items } & Mean & $\begin{array}{l}\text { Std. } \\
\text { Dev. }\end{array}$ & SD & D & I & A & SA \\
$\begin{array}{l}\text { 1. I would ordinarily cheat in an examination(R) } \\
\text { 2. I have never cheated in an examination }\end{array}$ & 1.83 & 1.19 & 56.0 & 23.1 & 9.1 & 5.1 & 6.7 \\
$\begin{array}{l}\text { 3. If I find a fellow student cheating in an } \\
\text { examination I would call the attention of the } \\
\text { invigilator }\end{array}$ & 2.22 & 1.18 & 34.9 & 28.2 & 23.1 & 7.8 & 6.0 \\
$\begin{array}{l}\text { 4. It is an appropriate behaviour if a student reports } \\
\text { another student cheating in an examination }\end{array}$ & 2.92 & 1.37 & 20.0 & 20.2 & 24.9 & 17.6 & 17.3 \\
$\begin{array}{l}\text { 5. I would seek assistance from a neighbour in an } \\
\text { examination if necessary (R) }\end{array}$ & 2.55 & 1.28 & 24.8 & 30.9 & 17.6 & 17.6 & 9.1 \\
$\begin{array}{l}\text { 6. It is not my business to report a student cheating in } \\
\text { examination or alert the invigilators (R) }\end{array}$ & 3.46 & 1.39 & 13.4 & 12.2 & 20.7 & 22.4 & 31.3 \\
$\begin{array}{l}\text { 7. All students cheat to some extent in examinations } \\
\text { only the careless ones get caught(R) }\end{array}$ & 2.71 & 1.43 & 28.1 & 21.1 & 18.4 & 17.1 & 15.3 \\
$\begin{array}{l}\text { 8. Religious belief does not have anything to do with } \\
\text { examination conduct (R) }\end{array}$ & 3.03 & 1.51 & 24.4 & 14.9 & 17.1 & 20.0 & 23.6 \\
9. Student must pass examinations by all means(R) & 3.48 & 1.39 & 12.6 & 14.0 & 17.6 & 23.8 & 32.0 \\
\hline
\end{tabular}

[Note: SD - Strongly Disagree; D - Disagree; I - Indifferent; A - Agree; SA - Strongly Agree]

(R) - Denotes reversed scored items. 
There may be a number of reasons for the seeming apathy of the students to examination misconduct even when they perceive the behaviour as inappropriate. First is the possibility that students are not convinced that the invigilators are doing a thorough and proper job. It is equally conceivable that the peer sanctions on students who identify others for sanction is high and unbearable. These are strong reasons why students may believe that while his/her duty ends with proper conduct in an examination, the onus rests on the examiner/invigilator to ensure that everyone abides by the rules governing examinations. It is equally the examiner/invigilators responsibility to ensure strict invigilation that would make such misconduct difficult or impossible, while the university should also impose stiff sanctions that would make examination misconduct unattractive.

Factor analysis was used as a data reduction tool and as a technique to establish the construct validity of the measure of examination misconduct. Table IV shows the nine items that measures examinations misconduct. The result of the factor analysis is shown in Table V. The Principal Components Analysis methods for initial factor extraction and Varimax method rotation was applied. Three factors were identified as key dimensions of examination misconduct. These factors are named as cheating behaviour (four items), intervention (three items) and desperation (two items). Each factor has factor scores higher than $+/-0.50$, which demonstrates significant evidence about correlations between the items and each factor.

\section{Table V: Factor Analysis of the Examination Misconduct Items ${ }^{\mathrm{a}}$}

\section{Items and Factor Descriptions}

Factor 1: Cheating Behaviour

2. I have never cheated in an examination

5. I would seek assistance from a neighbour in an examination if necessary

1. I would ordinarily cheat in an examination

7. All students cheat to some extent in examinations only the careless ones get caught

Factor 2: Intervention

3. If I find a fellow student cheating in an examination I would call the attention of the invigilator

4. It is an appropriate behaviour if a student reports another student cheating in an examination

6. It is not my business to report a student cheating in examination or alert the invigilators

Factor 3: Desperation

9. Student must pass examinations by all means

8. Religious belief does not have anything to do with examination conduct

Explained variance per Factor

Cumulative percentage variance

Extraction Methods: Principal Component Analysis

Rotation Method: Varimax with Kaiser Normalization. ${ }^{\text {a }}$ Rotation converged in 6 iterations.

Factors loadings below 0.4 are suppressed in the above table.

Dancey and Reidy (2002) had noted that when performing factor analysis, at least 100 participants should be used and the study should have five times as many participants as variables. Both criteria were met by this study with a nine-item measure and 450 respondents. The percentage of total variance of all nine items explained by the three factors is about 54 
percent. The factor analysis shows evidence of construct validity for the measure of examination misconduct and a reliability coefficient (Cronbach alpha) of 0.87. Moreover, the significant but not too high correlation coefficient with other ethical constructs: perception of business ethics and ethical value assessment (see Table III) is an indication of convergent validity and, to a limited extent, discriminant validity (Churchill, 1995; Cooligan, 1999). There is obviously need for a more rigorous investigation to confirm these tentative findings.

On the qualitative side of the data, the respondents were asked to give any other general comments on students' conduct and ethical behaviour in their university. A total of 152 representing about one third of the respondents responded to this item and the responses were varied. Nearly all responses alluded to the presence of students' examination misconduct in one way or another. The general responses expressed by over 40 percent of the respondents include: majority of students behave badly; the conduct of students is not good enough; cheating has to be discouraged at all cost; plagiarism in assignments and copying in test are preponderant and students should be of good conduct. The respondents also generally reported that students who are of good behaviour should be recognised and rewarded; they also noted that it is painful to see someone cheating when you are struggling to remember the answer. One respondent noted, "when lecturers set difficult examinations, it may lead to cheating but honestly we all want to proceed. Examination should not be a disciplinary tool but to test understanding”.

It is equally noteworthy that about 35 percent of the students indicated that students would not cheat if invigilation were strict and thorough; claiming that lecturers are never vigilant in invigilation; they called for stronger disciplinary actions to be taken on students that cheat; and a few (5\%) suggested that cameras should be installed in classrooms to check students cheating behaviour. On another note, some of the respondents (about 10\%) attributed the cheating behaviour to the conditions of living on campus, claiming that if the university administration listens to students' complaints, students will be of better behaviour. About 5 percent (eight respondents) noted that the corrupt practices in government are being reflected in students' behaviour. Two respondents indicated that, “...students are afraid to report others because of a possible threat to their lives"; another stated that, “...students who cheat in school often fail to perform later in their workplaces”; and yet another noted that, “...parental upbringing is really important in the conduct of the students”.

\section{DISCUSSIONS AND CONCLUSIONS}

Ethical issues are rather difficult and complicated to investigate. There is never an assurance that respondents are not giving socially desirable responses. It is therefore difficult to assert that the responses obtained reflect the true and sincere opinion and likely practices of the respondents. Maclagan (1998) in the concluding paragraph of his book 'Management and Morality' comments: "The key to managerial ethics is the development of individuals so that, ideally, they will possess the moral attributes required for the apprehension, appreciation and handling of ethical issues and dilemmas. To say this is to emphasise a human potential for independent moral judgement, rather than any need for enforced organisational rules and codes”.

The mission of a business school is to turn out professionally competent managers who have learnt to consider problems from a general management perspective and who have acquired a 
high sense of the moral and social responsibility their future position of power demands. It would be not just an irony but also a tragedy if future executives, at the end of a degree in business, were not excited by the challenges, responsibility and opportunities to contribute significantly to the business society through a career in business leadership. Is this assertion necessarily so? Are business students any more morally inclined than other students in universities/colleges? These among others are questions that deserve further empirical investigations.

Examination misconduct by itself may certainly not be of keen interest to management practitioners and decision makers. However, when viewed in the context of its possible relationship or causal link with managerial and/or business ethics it becomes considerably critical. Our findings demonstrated not only a strong association between examination misconduct and business ethics but also supports examination misconduct as predictive of business ethics explaining about 4 percent of the variance. The implications of such a linkage between academic ethics and business ethics are numerous including the managerial desire to create and sustain conditions in which people are likely to behave ethically, as well as, minimising conditions in which people might be tempted to behave unethically. Managerial decision making in several areas including recruitment and selection practices, establishment of high standards of ethical behaviour (not just rules), setting an impeccable ethical example at all times starting from the top, creating and maintaining a code of ethics and enforcing it fairly and consistently among others actions calls for caution as well as vigilance in their conception, articulation and implementation.

The three factors identified in the measurement of examination misconduct are perhaps a true reflection of the dimensions of this ethical issue. First, is the actual cheating behaviour, which involves the actual act of taking into the examination venue, or possessing whilst in the venue, books, notebooks, crib notes, duffle bags, cellular phones, mini-computers and any other unauthorised materials. It may also include aiding or attempting to aid, soliciting or attempting to do so from other candidates. This is the behaviour termed misconduct or malpractice and it is this ethical misconduct that is sanctioned. Of critical note, for instance, is the finding of Rawwas \& Isakson (2000) that opportunity to cheat is a good predictor of cheating behaviour. It is therefore crucial that this opportunity is unavailable to students while in examination. The second factor, which we named intervention, is based on the view that a student could also alert the examiner/invigilator or report another student engaged in misconduct. The strength of the ethical argument here is that ethics in an organisation is everyone's responsibility! There is no doubt that such whistleblowing efforts would go a long way in minimising the incidence of examination misconduct. The third factor, named desperation underscores the undesirability of "at all cost" mentality. The value of a university degree in emancipating the degree holder from imminent poverty, particularly in most developing countries, is towering. This should certainly not be at the cost of proper and acceptable conduct.

The penalties for misconduct as stated in the university regulations for both universities in this study are generally similar. Overall, the Swaziland regulation is stricter on first offenders depending on the gravity of the misconduct as a student may be dismissed for a serious case of misconduct even as a first offender. In Botswana, dismissal applies only for repeated misconduct. However, both universities provide opportunity of appeal for the erring students (University of Swaziland Calendar 2002/2003 and University of Botswana Calendar 2002/2003). 
It is perhaps noteworthy that in both faculties (of the universities) that constituted the sample for this study there is not a single course in business ethics. The initiation of a core course in 'Business Ethics' is a challenge that curriculum reviewers and university administrators should take seriously in many African universities where such courses do not presently exist. Rawwas \& Isakson (2000) gave a number of recommendations on some of the measures that could reduce the incidence of academic dishonesty particularly with respect to examinations. Of note is their call for the elimination of cheating opportunities and the need for more vigilance on the part of invigilators/professors. This suggests that there is much more that could still be done by faculty members particularly in the light of McCabe (1993) report that 55\% of faculty members polled felt that the typical faculty member would not be willing to take time and effort to investigate incidence of cheating, even though Roig \& Ballew (1994) found students tend to blame faculty members for widespread levels of cheating. A lot is expected by students from faculty members for the maintenance of high level of academic excellence. Consequently, when the pursuance of academic cheaters is left to a few faculty members, the danger is that such persons are singled out and negatively labelled by students. There are other factors which may discourage academics from pursuing misconduct cases. First, the burden of proof rests with the faculty member/professor. Second, this may require going the extra mile of writing reports and presenting or defending the cheating case at "University Misconduct Panel/Committees". Third, the resultant behaviour of all these is that many academics believe this is time wasting and are uncomfortable with it. These are perhaps some of the reasons why many academics might not be very keen in pursuing misconduct cases.

Business, indeed, could only be as moral as those in it. When individuals engage in unethical conduct, they often attempt to rationalise it. Some of the rationalisation often adduced includes the following: First, "everyone is involved! It therefore cannot be so wrong". For instance, if many students are involved in misconduct and few view it as negative conduct, then it may not be so wrong afterall! Students engage in misconduct in varying degrees and thus may begin to view the scourge as something for which no individual should be singled out and punished. The "everyone is doing it" - mentality was discussed by Gibson (2000). Second, is the view that "an individual cannot really make a difference; hence there is no need to call for intervention". So many students are involved and therefore it takes a courageous "whistleblower" to take the lead in exposing the "chronic cheater" - who is sometimes well known to colleagues. Individuals may argue that separation of duties, obligations and responsibilities take the task of alerting or reporting the erring student outside of their task. This obviously calls for invigilators/examiners to be vigilant in their task. Students do not want to become detectives and twitters for the good of the university/organisation. Third, the peer sanction may be strong. Other students may isolate and ostracise the whistleblower for picking out a fellow student. Such peer sanctions may be farreaching and traumatic which will be borne by the individual alone.

The other side of the argument, however, are those who hold the more ethically conservative view that maintaining a high level of ethical conduct is and should be everyone's responsibility. Such individuals may rationalise that first it is morally wrong to cheat in examinations. Second, that by assisting the system (e.g. invigilators/examiners) it may reduce the unethical behaviour of examination misconduct. Third, that it will eventually manifest in future performance when a student cheats to pass now as such individuals may lack the requisite knowledge to put into practice what they have not learnt! 
The implications of a causal linkage between academic ethics and business ethics from the foregoing discussion for the management practitioner are enormous. Some tentative questions may facilitate bringing these implications to fore. To what extent would the manifestation of cheating behaviour by students reflect in their ethical conduct at work? Would the intervention behaviour students' manifest in an examination misconduct situation be indicative of whistleblowing tendency? Does an expression of desperation by a student suggestive of a likely chronic unethical personality? These are three questions along the lines of the three factors (cheating behaviour, intervention and desperation) identified by the examination misconduct measure of this study. Perhaps, future studies would enhance our understanding of this linkage as well as determine the predictive capability of our measures.

This study like many others has a number of limitations. First, the study does not make a statistical comparison of the two countries because the nature of the data collected was cumulative and intended to spread the responses rather than compare it. Indeed, the means score of the study variables in both countries were nearly identical. Secondly, a qualitative follow-up interview, which was absent in this study, would enrich the findings of future efforts particularly with respect to adducing plausible reasons for the various choices made by respondents. Third, a wider university spread of the sample across various faculties may provide an opportunity to compare responses across different disciplines, which the present study did not do since only business students were sampled.

Several areas for further research are unwrapped by the present study. Future studies may benefit from a longitudinal investigation of ethical behaviour by doing a follow-up on students whose view has been sought on examination misconduct while in school and comparing this with their later ethical conduct and views as practising managers. To what extent, for instance, would those views have changed due to maturity, as well as on-the-job and real-life managerial experiences? There is also the possibility that religious affiliations and beliefs may significantly correlate with academic cheating. It would be interesting to find out in developing countries - especially those that are also multi-religious societies - to what extent would religiosity and spirituality affect cheating behaviour. Could there also be some connection between level of economic development, poverty and the incidence of examination misconduct/academic dishonesty? In societies where so much value is placed on academic qualifications and certificates, could the citizen students also be more desperate in their desire to obtain one? Also, the research data did not say much on the cultural dimension which may unlock other linkages on the academicbusiness ethics linkage and this could be fully explored in future studies.

In sum, the present study has demonstrated that misconduct in examination is measurable and that it is associated with other measures of ethical conduct. The scale developed and tested in this study builds on the need to enhance the credibility of academic programmes by ensuring high standards of ethical conduct among the students. It is naïve to claim that this is the duty of certain persons. Rather, it is the duty of all academics to take the challenge as part of their contribution to the sustenance of the system. Management academics and practitioners should be interested in the issues raised in this paper, the former because of the importance of enhancing the quality of their academic programmes as well as ensuring highest levels of ethical conduct among their students and staff; while the latter should be concerned as an ultimate consumer of the product of the academic institutions. Management practitioners would be alerted in their 
hiring, placement and induction efforts as well as in their pursuit of ensuring ethical practices and/or monitoring ethical behaviour within the organisation. Much as the results are reassuring, further study is required, as business managers in the future would be increasingly expected to play active roles in enhancing ethical standards of business and society.

\section{REFERENCES}

Aldag, R.J. \& Stearns, T.M. (1991), Management. Cincinnati, OH: South Western.

Ameen, E.C; Guffey, D.M. \& McMillan, J.J. (1996), "Gender differences in determining the ethical sensitivity of future accounting professionals", Journal of Business Ethics, Vol. 15, pp. 591-597.

Baird, J.S. (1980), “Current trends in college cheating”, Psychology in the Schools, Vol. 17, No. 4, pp. 515-522.

Baron, P. Hammerbacher, I. \& Paderon, E.S. (1984), Business students' perception of corporate ethical behavior (Report No. HE 017580), New Rochelle. NY: Centre for the Advancement of Public Policy.

Brown, B.S. (1995), "The academic ethics of graduate students: A survey”, Journal of Education for Business, Vol. 70, No. 3, pp. 151-157.

Brown, B.S. (2000), “The academic ethics of graduate business students: 1993 to 1998”, Journal of Applied Business Research, Vol. 16, No. 4, pp. 105-113.

Buckley, M.R.; Wiese, D.S.; et al. (1998), "An investigation into the dimensions of unethical behavior”, Journal of Education for Business, Vol. 73, No. 5, pp. 284-291.

Bunn, D.N.; Caudill, S.B. \& Gropper, D.M. (1992), "Crime in the classroom: An economic analysis of undergraduate students cheating behavior", Journal of Economic Education, Vol. 23, pp. 197-207.

Burton, B.K. \& Near, J.P. (1995), "Estimating the incidence of wrongdoing and whistleblowing: Results of a study using randomised response technique", Journal of Business Ethics, Vol. 14, pp. 17-30.

Churchill, G.A. Jr. (1995), Marketing Research: Methodological Foundations, Sixth edition, Fort Worth: The Dryden Press.

Clugston, M; Howell, J.P. \& Dorfman, P.W. (2000), "Does cultural socialization predict multiple based and foci of commitment?” Journal of Management, Vol. 26, No. 1, pp. 5-20.

Cole, B.C. \& Smith, D.L. (1995), "Effects of ethics instruction on the ethical perceptions of college business students", Journal of Education for Business, Vol. 70, No. 6, pp. 351-357. 
Cooligan, H. (1999), Research Methods and Statistics in Psychology, Third edition, London: Hodder \& Stoughton.

Dancey, C.P. \& Reidy, J. (2002), Statistics without Maths for Psychology, Second Edition, London: Prentice Hall.

Dorfman, P.W \& Howell, J.P. (1988), "Dimension of national culture and effective leadership patterns: Hofstede revisited", Advances in International Comparative Management, Vol. 3, pp. 127-150.

Gibson, K. (2000), “Excuses: Moral slippage in the workplace”, Business Horizon, Vol. 43, No. 6, pp. 65-70.

Glenn, J.R., Jr. (1992), "Can a business and society course affect the ethical judgement of future managers?” Journal of Business Ethics, Vol. 11, pp. 217-223.

Hofstede, G. (1980), Culture consequences: International differences in work related values, Beverly Hills, CA: Sage.

Hofstede, G. (1991), Cultures and organisations: Software of the mind, London: McGraw-Hill.

Khan, S.R. (1997), "Past performances and administered tests as university admissions criteria in Pakistan”, Journal of Asian Economics, Vol. 8, No. 1, pp. 67-77.

Leming, J.S. (1980), "Cheating behavior, subject variables, and components of the internalexternal scale under high and low risks conditions”, Journal of Educational Research, Vol. 74, pp. 83-87.

Lin, C.Y. (1999), “A comparison of perception about business ethics in four countries”, Journal of Psychology, Vol. 133, No. 6, pp. 641-655.

McCabe, D.L. (1993), "Faculty responses to academic dishonesty: The influence of student honor codes”, Research in Higher Education, Vol. 34, No. 5, pp. 647-658.

McCabe, D.L. \& Trevino, L.K. (1993), “Academic dishonesty: Honor codes and other contextual influences”, Journal of Higher Education, Vol. 64, No. 5, pp. 523-538.

Maclagan, P. (1998), Management and Morality, London: Sage.

Meade, J. (1992), “Cheating: Is academic dishonesty par for the course?” Prism, Vol. 1, No. 7, pp. 30-32.

Michaels, J.W. \& Miethe, T.D. (1989), “Applying theories of deviance to academic cheating”, Social Science Quarterly, Vol. 70, No. 4, pp. 870-885. 
Nuss, E.M. (1984), “Academic integrity: Comparing faculty and student attitudes”, Improving College and University Teaching, Vol. 32, No. 3, pp. 140-144.

Peppas, S.C. \& Peppas, G.J. (2000), "Business ethics in the European Union: a study of Greek attitudes”, Management Decision, Vol. 38, No. 6, pp. 369-376.

Preble, J.F. \& Reichel, A. (1988), "Attitudes towards business ethics of future managers in the U.S. and Israel”, Journal of Business Ethics, Vol. 7, pp. 941-949.

Rawwas, M.Y.A. \& Isakson, H.R. (2000). "Ethics of tomorrow's business managers”, Journal of Education for Business, Vol. 75, No. 6, pp. 321-331.

Robertson, D. (1993). “Empiricism in business ethics: Suggested research direction”. Journal of Business Ethics, Vol.12, pp. 585-599.

Roig, M. \& Ballew, C. (1994), "Attitudes towards cheating of self and others by college students and professors", The Psychological Record, Vol. 44, No. 1, pp. 3-10.

Schlegemilch, B. \& Roberson, D. (1995), "The influence of country and industry on ethical perceptions of senior executives in the U.S. and Europe”, Journal of International Business Studies, $4^{\text {th }}$ quarter, pp. 859-881.

Sikula, A. \& Costa, A. (1994), “Are women more ethical than men?” Journal of Business Ethics, Vol. 13, pp. 859-871.

Small, M.W. (1992), "Attitude towards business ethics held by Western Australian students: A comparative study”, Journal of Business Ethics, Vol. 11, pp. 745-752.

Stanga, K.G. \& Turpen, R.A. (1991), "Ethical judgement on selected accounting issues: an empirical study”, Journal of Business Ethics, Vol. 10, pp. 739-747.

Stark, A. (1993), "What's the matter with business ethics?" Harvard Business Review, Vol. 71, No. 3, pp. 38-48.

Tittle, C.R. \& Rowe, A.R. (1973), "Moral appeal, sanction threat, and deviance: An experimental test”, Social Problems, Vol. 20, pp. 488-498.

Tsalikis, J. \& Ortiz-Buonafina, M. (1990), "Ethical beliefs differences of males and females", Journal of Business Ethics, Vol. 9, pp. 509-517. 